The evolution of informed liquidity provision and consumption: Evidence from an

\author{
order driven market ${ }^{1}$
}

By

\author{
D. E. Allen* M. Wee** and J. W. Yang** \\ *School of Accounting, Finance and Economics, Edith Cowan University \\ **UWA Business School, University of Western Australia.
}

Jan 2013

Preliminary - Please do not quote

\begin{abstract}
We investigate the provision of liquidity by different trader types on the Australian Securities Exchange using data that spans an extended sample period of 2003 to 2009. We find the familiar intraday U-shaped pattern in order volume and frequency where the lunch time session is associated with a lower level of order placement activity. We also find institutional traders use more limit orders than market orders and that their relative use of limit to market orders is higher than retail traders. The use of limit orders by institutional traders has increased substantially in 2009 and reflects the growth in algorithmic and high frequency trading. When studying the price impact of market orders, we find institutional traders are better informed than retail traders. While we do not find the provision of liquidity by institutional traders to be driven by information, there is some evidence from 2009 that liquidity provision is information driven.
\end{abstract}

JEL Classifications : G10; G12; G13

Keywords : Evolution of Liquidity; informed trader; limit order; information asymmetry

\footnotetext{
${ }^{1}$ The authors would like to acknowledge the excellent research assistance of Tristan Boyd and SIRCA for kindly providing the data. The funding support of a strategic research grant by the Faculty of Business and Law at Edith Cowan University is gratefully acknowledged.

**Corresponding Author: Joey Wenling Yang, Discipline of Accounting and Finance, University of Western Australia, 35 Stirling Hwy, Crawley, WA 6009. Tel 61864882916, Fax 61864881047, email: joeywenling.yang@uwa.edu.au.
} 


\section{The evolution of informed liquidity provision and consumption: Evidence from an order driven market}

\section{Introduction}

The issue of liquidity provision and consumption in securities markets is a significant source of concern for market participants, regulators and stock exchanges. With the uprise of algorithmic and high frequency traders, it is unclear which traders are the providers of liquidity when the need for liquidity is most wanted. This is even more pertinent in an order driven markets such as the Australian Stock Exchange ${ }^{2}$ (ASX) where the viability of the market depends entirely on public traders providing liquidity when required. This paper examines the provision of liquidity by institutional and retail traders over an extended period spanning 2003 to 2009. The earlier part of the sample period being one where algorithmic and high frequency traders are less prevalent. The choice of the sample period allows us to study how markets would operate if regulators and exchangers place a ban on these market participants.

In examining the provision of liquidity, we study the contribution by institutional and retail traders over the trade day and how their provision of liquidity varies with market conditions. It is especially important to understand the motive behind institutional investors' liquidity provision and consumption as these investors constitute the majority of daily order submissions and trading volume in the market. This forms the first objective of the paper.

\footnotetext{
${ }^{2}$ With a total market capitalisation of approximately A $\$ 1.3$ trillion (December 2011), the ASX equity market is currently ranked sixth largest in the world in terms of free float market capitalisation (see ASX Market Brochure).
} 
The second objective is to examine whether institutional investors' role in liquidity provision and consumption is information driven. In other words, are they informed?

Prior research on liquidity provision focuses on the order choice strategy of informed and uninformed traders. Although a large number of theoretical models propose that informed traders would always use market orders given the short lived nature of their information, this proposition was challenged by a recent experimental study by Bloomfield, O’Hara and Saar (2005) and by recent empirical studies that show a preference for limit orders by informed traders (Anand, Chakravarty and Martell 2005; Chakravarty and Holden 1995). Wang and Zu (2008) provide the theoretical rationale for this preference and Kaniel and Liu (2004) argue that limit orders of informed traders are in fact more informative than their market orders.

Our paper contributes to the existing literature in three ways. First, we examine the liquidity provision and order choice strategy of institutional traders and the change in the strategies over the course of the trading day. Our study complements the work by Anand, Chakravarty and Martell (2005), who test the experimental study of Bloomfield, O’Hara and Saar (2005) and provide empirical evidence from a hybrid market. Our paper differs in that it investigates the provision of liquidity on an electronic limit order market and provides empirical evidence to investigate the hypotheses proposed by Bloomfield, O’Hara and Saar (2005) that are based on an electronic market setting.

Second, we extend the study by Anand, Chakravarty and Martell (2005) by investigating their assumption that institutional traders are informed. Specifically, we test whether institutional traders' liquidity provision (by examining orders of different aggressiveness) is driven by information. Prior studies suggest orders placed by informed traders cause larger and more 
prolonged price impact. We examine the degree of the informed liquidity provision through the price impact of orders in each aggressiveness categories. Last, we examine the order submission by different trader types over an extended period, allowing us to document any changes in order submission that may have been brought about due to the wide spread use of algorithmic and high frequency trading by institutional traders.

Using a dataset comprising stocks in the ASX50 from the years 2003, 2006 and 2009, we find the familiar intraday U-shaped pattern in order volume and frequency where the lunch time is associated with a lower level of order placement activity. We also find institutional traders place more limit orders than market orders and that institutional traders are more likely to use limit than market orders compared to retail traders. This suggests institutional traders play a vital role in the provision of liquidity on the ASX. ${ }^{3}$ The use of limit orders by institutional traders has increased substantially in 2009 and is likely to reflect the growth in algorithmic and high frequency trading. We do not find a similar increase in the use of limit orders by retail traders.

When studying the price impact of market orders using five- and 15-minute horizons, we find evidence to suggest institutional traders are better informed than retail traders. However, we do not find similar results when examining the limit orders placed by the different trader types. In particular, we find the price impact of limit orders is greater for the institutional traders only when using data from a later sample period, i.e., 2009. This is likely associated with the use of algorithmic and high frequency trading where computers are used to profit from short term market making.

\footnotetext{
${ }^{3}$ Future version of this paper will study the likelihood of execution of limit orders placed by institutional and retail traders.
} 


\section{Related Literature}

The earlier studies on trading strategies suggests informed traders use market orders (Bloomfield, O’Hara and Saar 2005; Glosten 1994; Rock 1990; Seppi 1990). These studies often assume trading in a dealer market, traders are eager to act on the information that they possess, and the information is often short-lived. However, more recent studies have shown informed traders also use limit orders, sometimes even more than market orders (Beber and Caglio 2005; Bloomfield, O’Hara and Saar 2005).

Harris (1998) predicts that the use of market orders by informed traders will be influenced by their opinion on the persistence of their informational advantage and by transaction costs. For example, if they possess relatively longer-lived information and a wider spread may this may outweigh non-execution risk and encourage informed traders to prefer a combination of both market and limit orders. Bloomfield, O'Hara and Saar (2005) use an experimental market setting to investigate the evolution of liquidity in an electronic limit order market. Bloomfield, O'Hara and Saar (2005) form the view market price is more likely to differ from the true value by a greater extent early on, and that informed traders will use market orders to "pick-off" differences during this "window of opportunity" if mispricing outweighs the cost of immediacy.

As prices systematically update during the trading period an informed trader can instead place limit orders around the true value to earn the bid-ask spread. Bloomfield, O'Hara and Saar (2005) point out that, in comparison to liquidity traders, informed traders face a far lower risk of adverse selection, the informational advantage of informed traders allows them 
to price limit orders more aggressively, thereby reducing non-execution risk. It is found that in total informed traders submit more limit orders than liquidity traders, and the difference is statistically significant.

Anand, Chakravarty and Martell (2005) empirically investigate the evolution of liquidity in the manner of Bloomfield, O'Hara and Saar (2005) using a sample of NYSE stocks. They find that institutional (informed) traders price their limit orders more aggressively than retail (liquidity) traders. Over the course of trading day, institutional traders appear to initially use market orders to exploit their informational advantage to earn larger profits, and then to supply liquidity to earn the bid-ask spread.

Liquidity traders behave in a manner consistent with Harris (1998), by submitting relatively fewer limit orders as the trading period progresses. Harris (1998) predicts that early in the trading period, liquidity traders will typically prefer to use limit orders to avoid paying the cost of immediacy. As the close of trading approaches, non-execution risk increases, so they will switch to a greater proportion of market orders to ensure that their targets are achieved before the market closes. Amongst others, the paper by Lee, Lin, Roll and Subrahmanyam (2004) provides evidence that institutions are more likely to be informed traders, whilst individuals are more likely to be liquidity (or noise) traders.

We extend the work on order placement strategies by examining the relative use of market and limit orders by institutional and retail traders. We also extend the literature by examining whether limit orders placed by the different trader types are motivated by information. Most importantly, we extend the literature by documenting changes in the provision of liquidity by different traders over an extended sample period. 


\section{Data and method}

\subsection{Sample and data description}

We use order and trade information for all stocks in the S\&P/ASX 50 Index over three time periods: January 2 to June 30 2003, January 2 to June 302006 and January 2 to June 30 2009. ${ }^{4}$ Data is sourced from the Securities Industry Research Centre of Asia-Pacific (SIRCA). The top 50 stocks account for more than $65 \%$ of the market capitalization on the ASX. The dataset contains every order placed and trade executed, and records the following information: stock code, date, time, price, volume, trade indicator (buy/sell), order type (market or limit order), and order status (enter, amend/cancel or trade). The orders placed by institutional traders are extracted using broker classification information provided by the ASX.

To conduct the analysis we divide a trading day into 36 ten-minute intervals from opening 10:00:00 to closing 16:00:00. Data for the first ten-minutes (i.e., 10:00:00 to 10:10:00) after the opening are omitted to avoid any potential confounding effects due to the staggered market opening procedure in practice on the ASX. ${ }^{5}$ The twenty minutes before closing is excluded to circumvent contamination of results from the effect of traders' possible abnormal behaviour associated with the market close. ${ }^{6}$

\footnotetext{
${ }^{4}$ According to the ASX website, "The S\&P/ASX 50 index comprises the 50 largest stocks by market capitalisation in Australia. The constituent companies represent the biggest national and multi-national publicly listed companies in the Australian equity market. The S\&P/ASX 50 index places an emphasis on liquidity and investability."

${ }^{5}$ Opening takes place at 10:00 am. Securities open in five groups according to the starting letter of their ASX code. Each group opens two minutes after the previous group. The first group opens at 10:00 am \pm 15 seconds and the last group opens at 10:09 \pm 15 seconds.

${ }^{6}$ At 16:00 market is placed in the pre-closing single price auction (Pre-CSPA) phase, where trading stops and traders are only allowed to submit limit orders. A surge of market orders are usually observed before the PreCSPA, so orders placed in the last 20 minutes prior to the auction are excluded from our analysis.
} 


\subsection{Liquidity provision by different trader types}

By using ten-minute intervals, we are able to construct our intra-day variable, limit order submission rate, to investigate traders' order choice between limit and market orders over the trading day and examine the effects of market conditions such as the level of information asymmetry, the adverse selection risk, liquidity, and volatility over the course of the trading day on the order choice.

Since all traders in the market are exposed to similar market wide information and affected by market wide activity, it is likely their order choices are either correlated contemporaneously or dependent on one another's past order submission strategy. To capture the order placement dynamics, we use a vector autoregressive system to model the institutional and retail traders' limit order submission rate. The model is as follows:

$$
\begin{aligned}
& {\left[\begin{array}{l}
S I_{t} \\
S R_{t}
\end{array}\right]=\left[\begin{array}{l}
\alpha^{I} \\
\alpha^{R}
\end{array}\right]+\left[\begin{array}{ll}
\beta_{11} & \beta_{12} \\
\beta_{21} & \beta_{22}
\end{array}\right]\left[\begin{array}{llll}
S I_{t-1} & S I_{t-2} & S I_{t-3} & S I_{t-4} \\
S R_{t-1} & S R_{t-2} & S R_{t-3} & S R_{t-4}
\end{array}\right]+\left[\begin{array}{c}
\gamma^{I} \\
\gamma^{R}
\end{array}\right] \cdot N U M_{t-1}+\left[\begin{array}{c}
\theta^{I} \\
\theta^{R}
\end{array}\right] \cdot S Z_{t-1}} \\
& +\left[\begin{array}{l}
\chi^{I} \\
\chi^{R}
\end{array}\right] \cdot N O F_{t-1}+\left[\begin{array}{c}
\sigma^{I} \\
\sigma^{R}
\end{array}\right] \cdot V O L_{t-1}+\left[\begin{array}{c}
\rho^{I} \\
\rho^{R}
\end{array}\right] \cdot S P R D_{t-1}\left[\begin{array}{l}
\pi^{I} \\
\pi^{R}
\end{array}\right] \cdot \Delta O W N_{t-1} \\
& +\left[\begin{array}{c}
\mu^{I} \\
\mu^{R}
\end{array}\right] \cdot \Delta O P P_{t-1}+\left[\begin{array}{c}
\varphi^{I} \\
\varphi^{R}
\end{array}\right] \cdot \sum_{i=1}^{5} D T_{i, t}+\left[\begin{array}{c}
\omega^{I} \\
\omega^{R}
\end{array}\right] \cdot \sum_{i=1}^{49} D S_{i, t}+\left[\begin{array}{c}
\varepsilon_{t}^{I} \\
\varepsilon_{t}^{R}
\end{array}\right]
\end{aligned}
$$

Where $S I_{t}$ and $S R_{t}$ are limit order submission rate by institutional and retail traders, respectively. $S I_{t}\left(S R_{t}\right)$ is calculated as the ratio of limit orders submitted in the number of orders to the sum of market and limit orders submitted by institutional (retail) traders within time interval $t$. Since a larger $S I_{t}$ and $S R_{t}$ over a certain time interval indicate a greater proportion of limit orders submitted relative to market orders, meaning that traders have chosen to use limit orders, or provide liquidity, more than market orders, or consume 
liquidity, these two variables became a measure of order choice and liquidity provision. SI/SR ranges from $[0,1]$. SI/SR equals 1 if there are only limit orders submitted in a certain period, and SI/SR equals 0 if only market orders are placed. Specifically,

$$
\begin{aligned}
S I & =\frac{L M T_{\text {insto }}}{M K T_{\text {insto }}+L M T_{\text {insto }}} \\
S R & =\frac{L M T_{\text {retail }}}{M K T_{\text {retail }}+L M T_{\text {retail }}}
\end{aligned}
$$

Four lags are chosen as per the Akaike information criteria (AIC). Variables controlling for market conditions are number of orders submitted in the last interval $\left(N U M_{t-1}\right)$, net order flow $\left(N O F_{t-1}\right)$, the average order size $\left(S Z_{t-1}\right)$, the spread $\left(S P R D_{t-1}\right)$ being half of the difference between the best bid and ask price; volatility being computed as the sum squared returns over the interval, $V O L_{t-1}=\sum_{n} r_{n}^{2}$; and the average change in depth at the best bid and ask prices on the same side $\left(\Delta O W N_{t-1}\right)$ as the order, and the opposing side $\left(\triangle O P P_{t-1}\right)$ of the order immediately before the order submission. ${ }^{7}$ To test the significance of time-of-the-day pattern, five dummy variables, each representing an hour of the day, are included $(D T) .{ }^{8}$ In addition, panel regression with fixed effects is estimated, similar to the least squares dummy variable model (LSDV), in recognition of stock specific factors.

\footnotetext{
${ }^{7}$ The change in depth is calculated for each order placed, and an average is obtained for each 10-minute time interval.

${ }^{8}$ The fourth hour, 13:00-14:00, is left out to avoid singularity in estimation.
} 


\subsection{Informativeness of orders placed by institutional and retail traders}

To study the informativeness of orders placed by institutional and retail traders, we examine the price impact of the orders place by the different traders. Price impact is measured by the change in the midpoint price from the time of order submission to five (15) minutes after.

$$
\triangle M P P=B S_{-} \text {Flag } \times\left(M P P_{t+5}-M P P_{t}\right)
$$

Where MPP is the mid-point price computed as the average of the best bid and ask at the time the order is place. BS_Flag equals 1 if the order is a buy and -1 if the order is a sell.

In order to control for the effects of order size and order aggressiveness, we examine the price impact of the order placed by the different traders in a regression model. Similar to the submission rate model, we use a panel regression with fixed effects in recognition of stock specific factors.

$$
\Delta M P P_{i}=\alpha+\beta S Z_{i}+\chi D I M_{i}+\delta D A M_{i}+\varphi D I_{n s t o}+\varepsilon_{i}
$$

Where DIM is a dummy variable that takes on the value of 1 for in-the-market orders, DAM is a dummy variable that takes on the value of 1 for at-the-market orders, and DInsto is a dummy variable that takes on the value of 1 for orders placed by institutional traders. 


\section{Results}

4.1 Intraday order placement choice of institutional versus retail traders

Figure 1 shows the use of market and limit orders by institutional and retail traders during the trade day. The figures in the first row show the orders submission measured by the number of shares, the figures in the second row show the number of orders placed, and the figures in the third row shows the average size of orders placed. In each figure, we also graph the various measures for the three sub-sample periods 2003, 2006 and 2009 separately.

[Insert Figure 1 about here]

A general observation from the figures is the greater likelihood by both groups of traders to use limit orders instead of market orders; this is regardless of the metric used to measure volume (i.e., VOL and NUM). ${ }^{9}$ The greater use of limit orders is likely a characteristic of the order-driven market examined where trading on the market will only occur if traders are willing to place limit orders. In addition, the figures show institutional traders are relatively more active than the retail traders and institutional traders supply a larger proportion of the limit orders. We examine the traders' relative use of limit orders and informativeness of the limit orders later.

The widely documented ' $U$ ' shaped pattern in trading volume and volatility in prior studies is also evident in the figures for order submission (VOL) and submission frequency (NUM). There is relatively more order placement activity in the morning and late afternoon compared

\footnotetext{
${ }^{9}$ In future versions, we will be measuring the volume of executed versus unexecuted limit orders.
} 
to the lunch hours (i.e., 12noon - 2pm). This is for both market and limit orders, and also for retail and institutional traders. By contrast, the pattern in order size is comparatively less distinct. While the ' $U$ ' shaped patterns documented are evident in all three subsample periods (i.e., 2003, 2006 and 2009), there is a substantial increase in the number of orders (both market and limit) placed by institutional traders in 2009. This is accompanied by a substantial decrease in the size of orders placed by institutional traders. This is likely to be associated with the increased use of algorithmic and computerised trading where a large number of smaller orders are automatically generated by computer algorithms. We do not see similar increase in order submission and decrease in order size for orders placed by retail traders.

Table 1 shows the use of limit orders and market orders during the three sessions: morning (10:10-12:10), lunch (12:10-14:10), and afternoon (14:10-16:00). The U-shaped pattern shown in Figure 1 for order volume and order submission frequency is again evident. Untabulated results show limit orders placed by institutional traders constitute $47 \%$ of the total order volume and market orders constitute $33 \%$ of the total order volume. Unsurprisingly, approximately $84 \%$ of the total volume on the market is attributed to institutional brokers and traders. The statistics shows institutional traders plays a significant role in the provision and consumption of liquidity on an order-driven market such as the ASX.

\section{[Insert Table 1 about here]}

When we examine the three sessions, we see both trader types are more active in trading and order submission in the morning and afternoon as opposed to the middle of the day. In particular, Panel B shows institutional traders submit relatively more limit orders in the afternoon than retail traders. For example, in 2003, 44 per cent of the orders are limit orders 
placed by institutions, compared with 15 per cent of the orders are limit orders placed by retail traders. There is also a substantial increase in the number of limit orders placed by institutional traders in 2009. The last two hours before closing is also the period of highest trading activity with relatively more market orders placed by institutional traders.

\subsection{The determinants of order choice for institutional and retail traders}

The choice of a certain type of order to place in the market determines whether the trader is providing or demanding liquidity. Liquidity providers submit limit orders and liquidity consumers submit market orders. The distinctive patterns in order type choice between institutional and the retail traders provoke the interesting question of what determines their order choice decision. Is it the market-wide information, or institutional traders possess some private information as well, that causes institutional traders to be much more active at the opening and closing as opposed to the midday?

Panel A of Table 2 provides the summary statistics for the variables examined in model (1). The order choice variables, $S I$ and $S R$, indicate that institutional brokers use comparatively more limit orders than market orders (53.7\% in 2003, 69.5\% in 2006 and 84.1\% in 2009). By contrast, retail traders use comparatively less limit orders (34.4\% in 2003, 40.9.5\% in 2006 and $31.6 \%$ in 2009) and are more likely to use market orders when trading. Also, the likelihood of retail traders to use limit orders have not increased in 2009.

In Panel B, we present the Spearman correlation coefficients for the variables examined in Model (1). The results show all independent variables representing market conditions are 
correlated with future order choice of both types of traders, giving rise to a dynamic longterm relationship over time.

[Insert Table 2 about here]

The distinct intra-day pattern of order choice by institutional traders and the retail traders as shown in table 1 and figure 1 is further tested in this section. The VAR panel regression (with fixed effect between stocks) for order choice of the two groups of traders is estimated and results are presented in Table 3. The institutions' order choice, proxied by the ratio of their limit order on their total order submission, is regressed on the time-of-the-day dummies and the matrix of control variables. Significant coefficients for morning and afternoon dummy variables indicate a strong time dependence of institutional order submission choice. It is noted that the explanatory power of time-of-the-day dummy variables are significant even after controlling for order size, order submission frequency, volatility, transaction cost and the change in depth on both bid and ask side of the order book. Furthermore, the inter-day effect is significant even after the seasonal effect of the spread and the volatility is taken into account, indicated in the two sets of interaction variables, one between the volatility and the time-of-the-day dummies, and the other between the spread and the time-of-the-day dummies.

For the purpose of comparison, the order choice regression results for retail traders in the market are also presented in Table 3. First of all, most independent variables that predict the order submission choice of institutions also predict that of retails in the same direction, but to a different degree of significance. For instance, the limit order submission is still strong in the afternoon even after the effect of larger spread in the afternoon deduces more market orders 
is taken into account. Retail traders on the other hand are more sensitive to this effect, showing insignificant afternoon limit order submission dependence after the negative effect of large spread. Secondly, it is noticed that the depth on the same side encourages retail limit order submission, whereas this variable does not have any predictive power on institutions. This suggests that retail traders become impatient when they observe a thick depth on the same side, consistent with empirical findings of Ranaldo (2004) that patient traders become aggressive when the same-side depth becomes thicker. Thirdly, it is intriguing to see that even the same independent variables representing market conditions are used in both regressions, the resultant goodness of fit, $\mathrm{R}^{2}$, is far from the same. This is consistent with Wang and Zu (2008) and Bloomfield, O’Hara and Saar (2005)’s proposition that uninformed traders trade on information in the current limit order book, while informed traders trade on information about the value of the stocks.

[Insert Table 3 about here]

\subsection{The aggressiveness of limit orders by institutional vs. retail traders}

In Table 4, we present statistics on the use of orders of different aggressiveness. In particular, we classify the limit orders into three additional categories: (1) in-the-market orders, (2) atthe-market orders, (3) behind-the-market orders. Orders in all three categories are limit orders that are less aggressive than market orders with behind-the-market orders being the least aggressive. In-the-market orders are bid or ask limit orders that are placed with prices between the best bid and ask on the market. At-the-market orders are limit sell (buy) orders that have a limit price that is equals to the best sell (bid) place on the market. Behind-the- 
market orders are limit sell (buy) order that have a limit price that is higher (lower) that the best sell (bid) on the market.

[Insert Table 4 about here]

Conditioned on the order examined is a limit order submitted by an institutional trader, it is likely that the limit order is an at-the-market limit order (see Panel A). While the proportion of the different limit orders used have remained generally stable over time, the number of behind-the-market limit orders used by institutional traders have increased in 2009 . Furthermore, the size of these orders has decreased substantially from 11,098 to 1,839 . The observed increased use of behind-the-market orders used by institutional traders is also evident for retail traders.

With respect to order size, we find institutions trade in larger sizes with their average market orders more than three times larger than their retail counterpart in 2003. However, the average market order submitted by institutional traders has decreased over the sample period. In 2009, market orders submitted by institutional traders are on average smaller than market orders submitted by a retail trader. The pattern of the limit order sizes is however similar across two trader types, where the smallest orders are observed between the best bid and ask prices, next behind the best quotes and the largest limit orders are placed at the best quotes. Secondly, in terms of order frequency, although both institutions and retails overall use more limit orders than market orders, the composition of their limit orders is remarkably different. While $56 \%$ of institutions limit orders are placed either on or better than the best quotes, $63 \%$ of retail limit orders are placed behind the market. (how to link it to previous regression results) ... 


\subsection{Price impact of orders}

To further investigate the proposition that institutional trades are motivated by information, we examine the price impact of institutional orders of differing aggressiveness and compare the price impact of institution orders to those of retail orders. The results for the univariate analysis are presented in Table 5.

[Insert Table 5 about here]

The results show, in 2003, market orders placed by institutional traders have greater price impact than orders placed by retail traders. For example, a market order placed in the morning placed by an institutional trader is associated with the mid-point price move of 0.59\% over a five-minute interval and $0.6 \%$ over a 15 -minute interval. By contrast, a market order placed by a retail trader moves the mid-point price by $0.46 \%$ over a five-minute interval and $0.44 \%$ over a 15 -minute interval.

Contrary to our expectations, we do not find consistent results to show limit orders placed by institutional traders to be associated with greater price impact. This suggests that limit orders placed by institutional traders are necessarily motivated by information. In the year-by-year analysis, we find evidence in the later years (i.e., 2006 and 2009) to show that in-the-market and at-the-market limits placed by institutional traders are more informative than those placed by retail traders.

We conduct additional analysis on the price impact of different limit order types used by the two different trader types in a regression model. The results for the regression corroborates our findings in the univariate analysis. 
[Insert Table 6 about here]

We find at-the-market limit orders are associated with larger price impact than the behindthe-market limit orders (i.e., the base case). In-the-market limit orders have the largest price impact among all the limit orders examined. We do not find limit orders placed by institutional traders to be associated with larger price impact in 2003 and 2006. However, limit orders placed by institutional traders in the 2009 subsample period are more informative.

\section{Conclusions}

This paper examines the provision and consumption of liquidity by institutional and retail traders on an electronic order driven market and investigates if the provision of liquidity by the different trader types are motivated by information. We first document the order placement strategies of institutional and retail traders over the course of the trading day and investigate if the patterns documented persist over a seven year period (using data from 2003, 2006 and 2009).

By using a dataset comprising stocks in the ASX50, we find the familiar U-shaped pattern in order volume and frequency where order placement activity is lowest during the lunch time period. We also find institutional traders place more limit orders than market orders and that institutional traders are more likely to use limit than market orders compared to retail traders. This suggests institutional traders play a pertinent role in the provision of liquidity on the ASX. In our study of the patterns over the three subsample periods, we find the use of limit 
orders by institutional traders has increased substantially in 2009 and is likely to be associated with the growth in algorithmic and high frequency trading. By contrast, we do not find a similar increase in the use of limit orders by retail traders.

In the second part of our analysis, we extend the study by Anand, Chakravarty and Martell (2005) by investigating the assumption that institutional traders are informed. Specifically, we test whether the limit orders strategies adopted by institutional traders are driven by information. We do so by measuring the price impact of orders in each aggressiveness categories. In our analysis of the price impact of market orders, we find evidence to suggest institutional traders are better informed than retail traders. However, we do not find the limit orders placed by the institutional traders to be motivated by information.

We also examine the order submission by different trader types over an extended period. This allows us to document any changes in order submission that may have been brought about due to the wide spread use of algorithmic and high frequency trading by institutional traders. In particular, we find the price impact of limit orders is greater for the institutional traders only when using data from the later sample period, i.e., 2009. This is likely to be an effect of algorithmic and high frequency where computers are used to profit from market making. 


\section{References}

Anand, A., S. Chakravarty, and T. Martell, 2005. Empirical evidence on the evolution of liquidity: Choice of market versus limit orders by informed and uninformed traders, Journal of Financial Markets 8, 288-308.

Anand, A., S. Chakravarty, and T. Martell, 2005. Empirical evidence on the evolution of liquidity: Choice of market versus limit orders by informed and uninformed traders, Journal of Financial Markets 8, 289-309.

Beber, A., and C. Caglio, 2005. Order submission strategies and information: Empirical evidence from the NYSE, Working paper, University of Pennsylvania.

Bloomfield, R., M. O'Hara, and G. Saar, 2005. The "make or take" decision in an electronic market: Evidence on the evolution of liquidity, Journal of Financial Economics 75, 165-199.

Bloomfield, R., M. O’Hara, and G. Saar, 2005. The "make or take” decision in an electronic market: Evidence on the evolution of liquidity, Journal of Financial Economics 75, 165-199.

Chakravarty, S., and C. W. Holden, 1995. An integrated model of market and limit orders, Journal of Financial Intermediation 4, 213-241.

Glosten, L. R., 1994. Is the electronic open limit order book inevitable?, Journal of Finance 49, 1127-1161.

Harris, L., 1998. Optimal dynamic order submission strategies in some stylized trading problems, Financial Markets, Institutions and Instruments 7, 1-76.

Kaniel, R., and H. Liu, 2004. So what orders do informed traders use?

Lee, Y.-T., Y.-J. Lin, R. Roll, and A. Subrahmanyam, 2004. Order imbalances and market efficiency: Evidence from the Taiwan stock exchange, Journal of Financial and Quantitative Analysis 39, 327-341.

Ranaldo, A., 2004. Order Aggressiveness in Limit Order Book Markets, Journal of Financial Markets 7, 53-74.

Rock, K., 1990. The specialist's order book and price anomalies, Working paper, Harvard University.

Seppi, D. J., 1990. Equilibrium Block Trading And Asymmetric Information, Journal of Finance 45, 73-94.

Wang, M. C., and L. P. Zu, 2008. Evolution of Liquidity: An Integrated Order Strategy Model of Uninformed and Informed Traders. 
Table 1 Descriptive statistics on order choice by institutional and retail traders

\begin{tabular}{|c|c|c|c|c|c|c|c|c|c|c|c|c|}
\hline \multirow[b]{3}{*}{ Year } & \multicolumn{6}{|c|}{ Institutional Traders } & \multicolumn{6}{|c|}{ Retail Traders } \\
\hline & \multicolumn{3}{|c|}{ Market orders } & \multicolumn{3}{|c|}{ Limit orders } & \multicolumn{3}{|c|}{ Market orders } & \multicolumn{3}{|c|}{ Limit orders } \\
\hline & 2003 & 2006 & 2009 & 2003 & 2006 & 2009 & 2003 & 2006 & 2009 & 2003 & 2006 & 2009 \\
\hline \multicolumn{13}{|c|}{ Panel A: Order Volume(million) } \\
\hline All Orders & 9,022 & 8,873 & 14,457 & 11,931 & 12,155 & 48,364 & 1,148 & 714 & 1,082 & 1,838 & 1,123 & 1,882 \\
\hline Morning & 3,425 & 3,763 & 5,570 & 4,743 & 5,169 & 17,570 & 520 & 324 & 484 & 883 & 547 & 903 \\
\hline Lunch & 1,375 & 1,392 & 2,759 & 1,850 & 2,082 & 11,157 & 221 & 147 & 238 & 382 & 234 & 427 \\
\hline Afternoon & 4,222 & 3,718 & 6,127 & 5,339 & 4,903 & 19,637 & 407 & 243 & 360 & 573 & 342 & 551 \\
\hline \multicolumn{13}{|c|}{ Panel B: Order Submission Frequency (000s) } \\
\hline All Orders & 508 & 812 & 3,950 & 836 & 2,094 & 23,069 & 252 & 231 & 256 & 284 & 364 & 288 \\
\hline Morning & 201 & 341 & 1,423 & 343 & 876 & 8,567 & 111 & 93 & 106 & 138 & 174 & 131 \\
\hline Lunch & 82 & 159 & 973 & 153 & 473 & 6,140 & 58 & 61 & 64 & 65 & 77 & 70 \\
\hline Afternoon & 225 & 312 & 1,554 & 340 & 745 & 8,361 & 83 & 77 & 86 & 82 & 114 & 87 \\
\hline \multicolumn{13}{|c|}{ Panel C: Average Size } \\
\hline All Orders & 17,515 & 10,572 & 3,565 & 13,869 & 5,627 & 2,072 & 4,470 & 3,021 & 4,153 & 6,440 & 3,066 & 6,448 \\
\hline Morning & 17,077 & 11,029 & 3,916 & 13,823 & 5,902 & 2,051 & 4,687 & 3,484 & 4,556 & 6,422 & 3,149 & 6,919 \\
\hline Lunch & 16,684 & 8,784 & 2,837 & 12,095 & 4,400 & 1,817 & 3,800 & 2,430 & 3,724 & 5,875 & 3,046 & 6,096 \\
\hline Afternoon & 18,785 & 11,902 & 3,942 & 15,688 & 6,580 & 2,349 & 4,923 & 3,149 & 4,178 & 7,024 & 3,004 & 6,330 \\
\hline
\end{tabular}

This table presents general descriptive statistics of market and limit orders placed by institutional and retail traders for all stocks in the S\&P/ASX 50 Index on the ASX from three sample periods: Jan 2 to Jun 30 2003, Jan 2 to Jun 302006 and Jan 2 to Jun 302009 . Panels A, B and C presents the statistics for the total submitted volume in shares, the number of orders, and the average order sizes, respectively. Within each panel, we provide intraday statistics where the trade day is divided into three sessions: morning (10:10-12:10), lunch (12:10-14:10), and afternoon (14:10-16:00). 
Table 2 Summary statistics and correlations

\begin{tabular}{|c|c|c|c|c|c|c|c|c|c|}
\hline & $S I_{t}$ & $S R_{t}$ & $N U M_{t-1}$ & $S Z_{t-1}$ & $S P R D_{t-1}$ & $V O L_{t-1}$ & $N O F_{t-1}$ & $\Delta O W N_{t-1}$ & $\triangle O P P_{t-1}$ \\
\hline \multicolumn{10}{|c|}{ Panel A: Summary statistics } \\
\hline \multicolumn{10}{|l|}{ Mean } \\
\hline 2003 & 0.537 & 0.344 & 9 & 6,068 & 0.0013 & 0.0003 & -0.114 & -407 & 522 \\
\hline 2006 & 0.695 & 0.409 & 20 & 2,035 & 0.0007 & 0.0004 & -0.083 & 30 & 19 \\
\hline 2009 & 0.841 & 0.316 & 119 & 394 & 0.0014 & 0.0006 & 0.006 & 9 & 10 \\
\hline \multicolumn{10}{|l|}{ Std Dev } \\
\hline 2003 & 0.076 & 0.122 & 6 & 9,443 & 0.0007 & 0.0005 & 0.065 & 3,465 & 3,479 \\
\hline 2006 & 0.044 & 0.119 & 11 & 2,264 & 0.0004 & 0.0007 & 0.067 & 59 & 53 \\
\hline 2009 & 0.030 & 0.140 & 65 & 932 & 0.0012 & 0.0008 & 0.037 & 33 & 26 \\
\hline \multicolumn{10}{|l|}{ Median } \\
\hline 2003 & 0.539 & 0.365 & 7 & 3,719 & 0.0012 & 0.0002 & -0.100 & 6 & 10 \\
\hline 2006 & 0.697 & 0.406 & 16 & 1,164 & 0.0007 & 0.0001 & -0.071 & 9 & 5 \\
\hline 2009 & 0.849 & 0.326 & 101 & 68 & 0.0010 & 0.0003 & 0.007 & 1 & 1 \\
\hline
\end{tabular}




\begin{tabular}{|c|c|c|c|c|c|c|c|c|c|}
\hline & $S I_{t}$ & $S R_{t}$ & $N U M_{t-1}$ & $S Z_{t-1}$ & $S P R D_{t-1}$ & $V O L_{t-1}$ & $N O F_{t-1}$ & $\Delta O W N_{t-1}$ & $\Delta O P P_{t-1}$ \\
\hline \multicolumn{10}{|c|}{ Panel B: Correlation coefficients } \\
\hline \multicolumn{10}{|l|}{ Year 2003} \\
\hline$S I_{t}$ & 1.00 & 0.02 & 0.12 & -0.02 & 0.06 & 0.01 & 0.00 & 0.02 & 0.02 \\
\hline$S R_{t}$ & & 1.00 & 0.10 & 0.00 & 0.10 & 0.01 & 0.01 & 0.00 & 0.00 \\
\hline$N U M_{t-1}$ & & & 1.00 & -0.13 & 0.04 & 0.01 & -0.08 & 0.00 & 0.00 \\
\hline$S Z_{t-1}$ & & & & 1.00 & -0.01 & -0.01 & -0.04 & -0.01 & 0.00 \\
\hline$S P R D_{t-1}$ & & & & & 1.00 & 0.07 & 0.02 & -0.02 & 0.00 \\
\hline$V O L_{t-1}$ & & & & & & 1.00 & 0.00 & 0.00 & 0.00 \\
\hline$N O F_{t-1}$ & & & & & & & 1.00 & 0.00 & 0.00 \\
\hline$\Delta O W N_{t-1}$ & & & & & & & & 1.00 & -0.62 \\
\hline$\Delta O P P_{t-1}$ & & & & & & & & & 1.00 \\
\hline \multicolumn{10}{|l|}{ Year 2006} \\
\hline$S I_{t}$ & 1.00 & 0.01 & 0.09 & -0.07 & 0.11 & 0.00 & 0.00 & 0.02 & 0.02 \\
\hline$S R_{t}$ & & 1.00 & 0.13 & -0.03 & 0.08 & 0.00 & 0.00 & 0.00 & 0.00 \\
\hline$N U M_{t-1}$ & & & 1.00 & -0.23 & 0.09 & -0.02 & -0.04 & 0.00 & 0.00 \\
\hline$S Z_{t-1}$ & & & & 1.00 & -0.02 & -0.01 & -0.04 & 0.00 & -0.02 \\
\hline$S P R D_{t-1}$ & & & & & 1.00 & 0.02 & 0.01 & -0.02 & 0.00 \\
\hline$V O L_{t-1}$ & & & & & & 1.00 & 0.00 & 0.00 & 0.00 \\
\hline$N O F_{t-1}$ & & & & & & & 1.00 & 0.00 & 0.00 \\
\hline$\Delta O W N_{t-1}$ & & & & & & & & 1.00 & -0.51 \\
\hline$\Delta O P P_{t-1}$ & & & & & & & & & 1.00 \\
\hline \multicolumn{10}{|l|}{ Year 2009} \\
\hline$S I_{t}$ & 1.00 & 0.01 & 0.11 & -0.07 & 0.10 & 0.00 & -0.01 & 0.02 & 0.02 \\
\hline$S R_{t}$ & & 1.00 & 0.08 & 0.02 & 0.07 & 0.01 & 0.00 & 0.00 & 0.00 \\
\hline$N U M_{t-1}$ & & & 1.00 & -0.29 & 0.03 & -0.01 & 0.00 & 0.00 & 0.00 \\
\hline$S Z_{t-1}$ & & & & 1.00 & 0.03 & -0.01 & -0.01 & -0.01 & -0.01 \\
\hline$S P R D_{t-1}$ & & & & & 1.00 & 0.06 & -0.02 & -0.02 & -0.02 \\
\hline$V O L_{t-1}$ & & & & & & 1.00 & 0.00 & 0.00 & -0.01 \\
\hline$N O F_{t-1}$ & & & & & & & 1.00 & 0.00 & 0.00 \\
\hline$\Delta O W N_{t-1}$ & & & & & & & & 1.00 & -0.21 \\
\hline$\Delta O P P_{t-1}$ & & & & & & & & & 1.00 \\
\hline
\end{tabular}


This table presents the summary statistics and Spearman correlation coefficients for all variables used in the model. Panel A presents the mean, standard deviation, and median for the variables in each of the three sub-sample periods. SI $(S R)$ is the ratio of limit orders submitted in the number of orders to the sum of market and limit orders submitted by institutional (retail) traders. SPRD is the spread, calculated as half of the difference between the best bid and ask price. Volatility, $V O L_{t-1}$, is computed as the sum of the squared returns over the interval, and the average change in depth at the best bid and ask prices on the same side $\left(\Delta O W N_{t-1}\right)$ as the order, and the opposing side $\left(\triangle O P P_{t-1}\right)$ of the order immediately before submission. Panel B presents the Spearman correlation coefficients for the dependent variables (the first two variables) in the current period, and the independent variables (the rest of the variables) in the lag period. The correlation coefficients are computed for each stock and then the average is presented in the table. 
Table 3 Panel Vector Autoregressive Regression (VAR) of institutional and retail traders order choice with fixed effects

\begin{tabular}{|c|c|c|c|c|c|c|}
\hline \multirow[b]{2}{*}{ Variables } & \multicolumn{3}{|c|}{ SI } & \multicolumn{3}{|c|}{$S R$} \\
\hline & Estimate & \multicolumn{2}{|c|}{$t$-stats } & Estimate & \multicolumn{2}{|c|}{$t$-stats } \\
\hline \multicolumn{7}{|l|}{ Panel A: 2003} \\
\hline Intercept & 0.344 & 59.4 & $* *$ & 0.197 & 29.6 & $* *$ \\
\hline$S I_{t-1}$ & 0.108 & 49.3 & $* *$ & 0.002 & 0.8 & \\
\hline$S I_{t-2}$ & 0.101 & 46.4 & $* *$ & 0.003 & 1.1 & \\
\hline$S I_{t-3}$ & 0.089 & 40.8 & $* *$ & 0.005 & 1.9 & $*$ \\
\hline $\mathrm{SI}_{t-4}$ & 0.079 & 36.4 & $* *$ & -0.001 & -0.3 & \\
\hline$S R_{t-1}$ & 0.001 & 0.8 & & 0.057 & 26.0 & $* *$ \\
\hline$S R_{t-2}$ & 0.001 & 0.6 & & 0.050 & 22.7 & $* *$ \\
\hline$S R_{t-3}$ & 0.000 & 0.0 & & 0.034 & 15.8 & ** \\
\hline$S R_{t-4}$ & -0.001 & -0.6 & & 0.037 & 17.1 & $* *$ \\
\hline$N O F_{t-1}$ & 0.001 & 0.6 & & 0.004 & 4.0 & $* *$ \\
\hline$N U M_{t-1}$ & 0.001 & 10.8 & $* *$ & 0.002 & 19.6 & $* *$ \\
\hline$S Z_{t-1}$ & 0.000 & 0.3 & & 0.000 & -1.5 & \\
\hline$S P R D_{t-1}$ & 33.495 & 21.2 & $* *$ & 57.203 & 31.4 & $* *$ \\
\hline$V O L_{t-1}$ & 0.086 & 4.2 & $* *$ & -0.009 & -0.4 & \\
\hline DT1 (10:10-11am) & 0.041 & 16.3 & $* *$ & 0.084 & 28.9 & ** \\
\hline DT2 (11-12noon) & 0.021 & 8.4 & $* *$ & 0.048 & 17.0 & $* *$ \\
\hline DT3 (12-1pm) & -0.043 & -17.8 & $* *$ & 0.023 & 8.2 & $* *$ \\
\hline DT5 (2-3pm) & 0.039 & 15.8 & $* *$ & 0.016 & 5.8 & $* *$ \\
\hline DT6 (3-4pm) & 0.012 & 4.4 & $* *$ & 0.024 & 7.8 & $* *$ \\
\hline$\Delta O W N_{t-1}$ & 0.019 & 10.3 & $* *$ & 0.003 & 1.6 & \\
\hline$\triangle O P P_{t-1}$ & 0.019 & 10.2 & $* *$ & 0.003 & 1.5 & \\
\hline \multicolumn{7}{|l|}{ Fit Statistics } \\
\hline R-square & 0.1167 & & & 0.1227 & & \\
\hline \multicolumn{7}{|c|}{$F$ Test for No Fixed Effects } \\
\hline & F value & $\operatorname{Pr}>F$ & & F value & $\operatorname{Pr}>F$ & \\
\hline & 56.36 & $<.0001$ & & 74.1 & $<.0001$ & \\
\hline \multicolumn{7}{|l|}{ Residual Tests } \\
\hline & Q-stats & Prob. & & Q-stats & Prob. & \\
\hline $\operatorname{lag}=1$ & 0.03 & 0.86 & & 0.25 & 0.62 & \\
\hline $\operatorname{lag}=12$ & 32.26 & 0.00 & & 17.58 & 0.13 & \\
\hline $\operatorname{lag}=24$ & 64.05 & 0.00 & & 29.91 & 0.29 & \\
\hline
\end{tabular}


Table 3 (Cont'd) Panel Vector Autoregressive Regression (VAR) of institutional and retail traders order choice with fixed effects

\begin{tabular}{|c|c|c|c|c|c|c|}
\hline \multirow[b]{2}{*}{ Variables } & \multicolumn{3}{|c|}{$S I$} & \multicolumn{3}{|c|}{$S R$} \\
\hline & Estimate & \multicolumn{2}{|c|}{$t$-stats } & Estimate & \multicolumn{2}{|c|}{$t$-stats } \\
\hline Intercept & 0.402 & 81.6 & $* *$ & 0.219 & 25.5 & $* *$ \\
\hline$S I_{t-1}$ & 0.128 & 56.5 & $* *$ & -0.009 & -2.2 & $*$ \\
\hline$S I_{t-2}$ & 0.110 & 48.4 & $* *$ & -0.016 & -4.1 & $* *$ \\
\hline$S I_{t-3}$ & 0.104 & 45.9 & $* *$ & -0.011 & -2.8 & $* *$ \\
\hline $\mathrm{SI}_{t-4}$ & 0.065 & 28.9 & $* *$ & -0.006 & -1.5 & \\
\hline$S R_{t-1}$ & 0.000 & -0.3 & & 0.166 & 73.2 & $* *$ \\
\hline$S R_{t-2}$ & -0.004 & -3.4 & $* *$ & 0.131 & 57.7 & $* *$ \\
\hline$S R_{t-3}$ & -0.004 & -2.9 & $* *$ & 0.117 & 51.2 & $* *$ \\
\hline$S R_{t-4}$ & -0.002 & -1.4 & & 0.102 & 45.1 & $* *$ \\
\hline$N O F_{t-1}$ & -0.001 & -1.2 & & -0.001 & -1.2 & \\
\hline$N U M_{t-1}$ & 0.001 & 21.9 & $* *$ & 0.001 & 20.7 & $* *$ \\
\hline$S Z_{t-1}$ & -0.007 & -8.7 & $* *$ & 0.000 & 0.3 & \\
\hline$S P R D_{t-1}$ & 88.645 & 45.4 & $* *$ & 77.040 & 22.6 & $* *$ \\
\hline$V O L_{t-1}$ & 0.074 & 5.9 & $* *$ & 0.062 & 2.8 & $* *$ \\
\hline DT1 (10:10-11am) & -0.010 & -5.7 & $* *$ & 0.039 & 12.8 & $* *$ \\
\hline DT2 (11-12noon) & -0.003 & -1.7 & & 0.007 & 2.4 & $*$ \\
\hline DT3 (12-1pm) & -0.011 & -6.5 & $* *$ & -0.012 & -4.1 & $* *$ \\
\hline DT5 (2-3pm) & -0.010 & -6.0 & $* *$ & 0.006 & 2.0 & $*$ \\
\hline DT6 (3-4pm) & -0.037 & -20.1 & $* *$ & 0.014 & 4.5 & $* *$ \\
\hline$\Delta O W N_{t-1}$ & 0.233 & 15.8 & $* *$ & 0.011 & 0.4 & \\
\hline$\Delta O P P_{t-1}$ & 0.257 & 18.8 & $* *$ & 0.038 & 1.6 & \\
\hline \multicolumn{7}{|l|}{ Fit Statistics } \\
\hline R-square & 0.1208 & & & 0.2027 & & \\
\hline \multicolumn{7}{|c|}{$F$ Test for No Fixed Effects } \\
\hline & $\begin{array}{r}\text { F value } \\
77.22\end{array}$ & $\begin{array}{r}\operatorname{Pr}>F \\
<.0001\end{array}$ & & $\begin{array}{r}\text { F value } \\
60.96 \\
\end{array}$ & $\begin{array}{l}\operatorname{Pr}>F \\
<.0001\end{array}$ & \\
\hline \multicolumn{7}{|l|}{ Residual Tests } \\
\hline & Q-stats & Prob. & & Q-stats & Prob. & \\
\hline $\operatorname{lag}=1$ & 0.08 & 0.86 & & 0.49 & 0.22 & \\
\hline $\operatorname{lag}=12$ & 42.75 & 0.00 & & 27.58 & 0.11 & \\
\hline $\operatorname{lag}=24$ & 48.75 & 0.00 & & 29.91 & 0.10 & \\
\hline
\end{tabular}


Table 3 (Cont'd) Panel Vector Autoregressive Regression (VAR) of institutional and retail traders order choice with fixed effec

\begin{tabular}{|c|c|c|c|c|c|c|}
\hline \multirow[b]{2}{*}{ Variables } & \multicolumn{3}{|c|}{ SI } & \multicolumn{3}{|c|}{$S R$} \\
\hline & Estimate & \multicolumn{2}{|c|}{$t$-stats } & Estimate & \multicolumn{2}{|c|}{$t$-stats } \\
\hline \multicolumn{7}{|l|}{ Panel C: 2009} \\
\hline Intercept & 0.329 & 132.8 & $* *$ & 0.276 & 23.9 & $* *$ \\
\hline$S I_{t-1}$ & 0.300 & 145.8 & $* *$ & 0.017 & 1.8 & \\
\hline$S I_{t-2}$ & 0.129 & 60.3 & $* *$ & -0.014 & -1.4 & \\
\hline$S I_{t-3}$ & 0.101 & 47.7 & $* *$ & -0.016 & -1.6 & \\
\hline $\mathrm{SI}_{t-4}$ & 0.079 & 38.6 & $* *$ & 0.001 & 0.1 & \\
\hline$S R_{t-1}$ & 0.000 & 0.5 & & 0.096 & 46.3 & ** \\
\hline$S R_{t-2}$ & -0.001 & -1.4 & & 0.076 & 36.4 & $* *$ \\
\hline$S R_{t-3}$ & 0.000 & -0.1 & & 0.056 & 26.8 & $* *$ \\
\hline$S R_{t-4}$ & -0.001 & -2.7 & ** & 0.051 & 24.5 & $* *$ \\
\hline$N O F_{t-1}$ & -0.001 & -2.4 & $*$ & 0.001 & 1.3 & \\
\hline$N U M_{t-1}$ & 0.005 & 23.1 & $* *$ & 0.000 & 16.5 & ** \\
\hline$S Z_{t-1}$ & -0.003 & -7.3 & $* *$ & 0.004 & 1.7 & \\
\hline$S P R D_{t-1}$ & -0.024 & -4.2 & $* *$ & 0.057 & 2.1 & * \\
\hline$V O L_{t-1}$ & 0.073 & 24.2 & $* *$ & -0.002 & -0.1 & \\
\hline DT1 (10:10-11am) & 0.009 & 15.3 & $* *$ & 0.080 & 30.3 & ** \\
\hline DT2 (11-12noon) & 0.002 & 4.0 & $* *$ & 0.037 & 14.7 & $* *$ \\
\hline DT3 (12-1pm) & 0.001 & 1.6 & & 0.017 & 6.9 & $* *$ \\
\hline DT5 (2-3pm) & -0.002 & -3.2 & $* *$ & 0.012 & 4.8 & $* *$ \\
\hline DT6 (3-4pm) & -0.023 & -39.2 & $* *$ & 0.037 & 13.6 & $* *$ \\
\hline$\Delta O W N_{t-1}$ & 0.098 & 15.9 & $* *$ & 0.044 & 1.5 & \\
\hline$\Delta O P P_{t-1}$ & 0.115 & 12.2 & $* *$ & 0.068 & 1.5 & \\
\hline
\end{tabular}

Fit Statistics

R-square 0.3197 0.1646

$F$ Test for No Fixed Effects

F value $\quad \operatorname{Pr}>\mathrm{F} \quad$ F value $\operatorname{Pr}>\mathrm{F}$

$\begin{array}{rrr}63.04<.0001<99.81 & <.0001\end{array}$

Residual Tests

$\operatorname{lag}=1$

Q-stats Prob.

Q-stats Prob.

$0.07 \quad 0.56$

$0.35 \quad 0.45$

$\operatorname{lag}=12$

$28.26 \quad 0.01$

$15.58 \quad 0.14$

$\operatorname{lag}=24$

$51.05 \quad 0.00$

$37.51 \quad 0.24$

This table presents panel regression results of institutional and retail order choice in a dynamic vector autoregressive system. All variables are stationary according to Kwiatkowski-Phillips-Schmidt-Shin (KPSS) test, and the lag length of four is supported by the Akaike information criterion (AIC). ** and * denote statistical significance at 5\% and 1\%, respectively. The Ljung Box Q-statistics test for higher order serial correlation in the residuals. 


\begin{tabular}{|c|c|c|c|c|c|c|c|c|c|}
\hline & \multicolumn{3}{|c|}{ Total } & \multicolumn{3}{|c|}{ Morning } & \multicolumn{3}{|c|}{ Afternoon } \\
\hline & 2003 & 2006 & 2009 & 2003 & 2006 & 2009 & 2003 & 2006 & 2009 \\
\hline \multicolumn{10}{|c|}{ Panel A: Institutional traders } \\
\hline \multicolumn{10}{|c|}{ Submitted volume (million) } \\
\hline Market orders & 10,361 & 1,157 & 16,872 & 3,928 & 523 & 6,351 & 4,860 & 412 & 7,293 \\
\hline Limit orders & 10,592 & 1,828 & 45,949 & 4,240 & 880 & 16,789 & 4,839 & 569 & 18,472 \\
\hline In the mkt & 593 & 78 & 1,687 & 265 & 40 & 690 & 235 & 21 & 656 \\
\hline At the mkt & 7,664 & 889 & 23,067 & 2,928 & 405 & 7,736 & 3,558 & 301 & 9,991 \\
\hline Behind the mkt & 2,335 & 861 & 21,195 & 1,046 & 434 & 8,363 & 1,046 & 247 & 7,825 \\
\hline \multicolumn{10}{|c|}{ Order submission frequency (000s) } \\
\hline Market orders & 539 & 253 & 4,298 & 212 & 112 & 1,535 & 240 & 83 & 1,695 \\
\hline Limit orders & 805 & 282 & 22,720 & 331 & 137 & 8,455 & 325 & 81 & 8,220 \\
\hline In the mkt & 116 & 25 & 1,368 & 54 & 13 & 596 & 41 & 6 & 434 \\
\hline At the mkt & 485 & 95 & 9,948 & 189 & 43 & 3,583 & 211 & 30 & 3,698 \\
\hline Behind the mkt & 204 & 162 & 11,404 & 89 & 81 & 4,276 & 74 & 44 & 4,088 \\
\hline \multicolumn{10}{|l|}{ Average order size } \\
\hline Market orders & 18,948 & 4,478 & 3,821 & 18,490 & 4,686 & 4,137 & 20,258 & 4,943 & 4,302 \\
\hline Limit orders & 10,502 & 5,877 & 1,784 & 10,752 & 5,960 & 1,757 & 11,654 & 6,254 & 1,907 \\
\hline In the mkt & 5,037 & 3,073 & 1,226 & 4,926 & 3,136 & 1,157 & 5,769 & 3,248 & 1,510 \\
\hline At the mkt & 15,372 & 9,303 & 2,288 & 15,510 & 9,357 & 2,159 & 16,892 & 9,955 & 1,510 \\
\hline Behind the mkt & 11,098 & 5,255 & 1,839 & 11,820 & 5,386 & 1,956 & 12,300 & 5,559 & 2,702 \\
\hline
\end{tabular}


Table 4 (Cont'd) Order aggressiveness summary

\begin{tabular}{|c|c|c|c|c|c|c|c|c|c|}
\hline & \multicolumn{3}{|c|}{ Total } & \multicolumn{3}{|c|}{ Morning } & \multicolumn{3}{|c|}{ Afternoon } \\
\hline & 2003 & 2006 & 2009 & 2003 & 2006 & 2009 & 2003 & 2006 & 2009 \\
\hline \multicolumn{10}{|l|}{ Panel B: Retail traders } \\
\hline \multicolumn{10}{|c|}{ Submitted volume (million) } \\
\hline Market orders & 1,157 & 716 & 1,083 & 523 & 325 & 485 & 412 & 243 & 360 \\
\hline Limit orders & 1,828 & 1,120 & 1,881 & 880 & 546 & 903 & 569 & 341 & 551 \\
\hline In the mkt & 78 & 52 & 60 & 40 & 26 & 30 & 21 & 15 & 17 \\
\hline At the mkt & 889 & 591 & 809 & 405 & 271 & 368 & 301 & 199 & 261 \\
\hline Behind the mkt & 861 & 478 & 1012 & 434 & 249 & 504 & 247 & 127 & 273 \\
\hline \multicolumn{10}{|c|}{ Order submission frequency (000s) } \\
\hline Market orders & 253 & 231 & 257 & 112 & 93 & 107 & 83 & 77 & 86 \\
\hline Limit orders & 282 & 364 & 287 & 137 & 173 & 130 & 81 & 114 & 87 \\
\hline In the mkt & 25 & 22 & 28 & 13 & 11 & 13 & 6 & 6 & 8 \\
\hline At the mkt & 95 & 228 & 79 & 43 & 104 & 33 & 30 & 79 & 27 \\
\hline Behind the mkt & 162 & 113 & 181 & 81 & 59 & 84 & 44 & 29 & 52 \\
\hline \multicolumn{10}{|c|}{ Average Order Size } \\
\hline Market orders & 4,478 & 3,022 & 4,146 & 4,686 & 3,485 & 4,548 & 4,943 & 3,149 & 4,172 \\
\hline Limit orders & 5,877 & 3,056 & 5,912 & 5,960 & 3,063 & 6,482 & 6,254 & 3,164 & 5,701 \\
\hline In the mkt & 3,073 & 2,386 & 2,115 & 3,136 & 2,340 & 2,285 & 3,248 & 2,590 & 2,084 \\
\hline At the mkt & 9,303 & 2,587 & 10,114 & 9,357 & 2,620 & 11,155 & 9,955 & 2,531 & 9,784 \\
\hline Behind the mkt & 5,255 & 4,196 & 5,506 & 5,386 & 4,230 & 6,005 & 5,559 & 4,370 & 5,236 \\
\hline
\end{tabular}

Note: this table presents a summary of orders submitted with different degree of aggressiveness during morning, lunchtime, and afternoon period, respectively, placed by institutional and retail traders over the sample period. Market orders are more aggressive then limit orders. The most aggressive limit orders are those placed between the best bid and ask prices, or orders in the market. Then it's the next is the orders placed at the best bid and ask prices, or orders at the market. The least aggressive orders are those placed behind the best bid and ask prices, or orders behind the market. 
Table 5 Price impact of orders

\begin{tabular}{|c|c|c|c|c|c|c|c|c|}
\hline \multirow{2}{*}{ 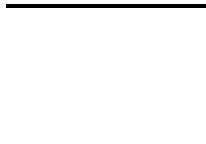 } & \multicolumn{4}{|c|}{5 minutes after order placement } & \multicolumn{4}{|c|}{15 minutes after order placement } \\
\hline & Insto & Retail & $\begin{array}{l}\text { Insto- } \\
\text { Retail }\end{array}$ & $t$-test & Insto & Retail & $\begin{array}{l}\text { Insto- } \\
\text { Retail }\end{array}$ & $t$-test \\
\hline
\end{tabular}

Panel A: 2003

Market Orders

$\begin{array}{lllllllll}\text { Morning } & 0.0059 & 0.0046 & 0.0013 & * * & 0.0060 & 0.0044 & 0.0016 & * * \\ \text { Lunch } & 0.0043 & 0.0031 & 0.0012 & * * & 0.0045 & 0.0032 & 0.0013 & * * \\ \text { Afternoon } & 0.0041 & 0.0035 & 0.0006 & * * & 0.0042 & 0.0034 & 0.0008 & * *\end{array}$

In-the-market orders

\begin{tabular}{|c|c|c|c|c|c|c|c|c|}
\hline Morning & 0.0058 & 0.0066 & -0.0008 & ** & 0.0055 & 0.0064 & -0.0009 & $* *$ \\
\hline Lunch & 0.0042 & 0.0051 & -0.0009 & ** & 0.0040 & 0.0048 & -0.0008 & ** \\
\hline Afternoon & 0.0043 & 0.0053 & -0.0010 & $* *$ & 0.0044 & 0.0050 & -0.0005 & $* *$ \\
\hline \multicolumn{9}{|c|}{ Orders at the best bid \& ask price } \\
\hline Morning & 0.0017 & 0.0018 & -0.0001 & ** & 0.0024 & 0.0022 & 0.0002 & $* *$ \\
\hline Lunch & 0.0007 & 0.0008 & -0.0001 & $* *$ & 0.0010 & 0.0009 & 0.0000 & $* *$ \\
\hline Afternoon & 0.0009 & 0.0011 & -0.0002 & $* *$ & 0.0013 & 0.0014 & -0.0001 & $* *$ \\
\hline \multicolumn{9}{|c|}{ Orders behind best bid \& ask price } \\
\hline Morning & -0.0010 & 0.0000 & -0.0010 & ** & -0.0013 & 0.0001 & -0.0014 & ** \\
\hline Lunch & -0.0005 & -0.0003 & -0.0002 & $* *$ & -0.0006 & -0.0004 & -0.0002 & $* *$ \\
\hline Afternoon & -0.0007 & -0.0001 & -0.0005 & ** & -0.0006 & 0.0000 & -0.0006 & $* *$ \\
\hline
\end{tabular}

Panel B: 2006

Market Orders

Morning

$$
0.0081
$$

0.0044

$0.0037 * *$

0.0080

0.0040

$0.0040 * *$

Lunch

$0.0050 \quad 0.0047$

$0.0003 * *$

0.0051

0.0041

$0.0011 * *$

Afternoon

$0.0051 \quad 0.0038$

$0.0013 * *$

0.0052

0.0026

$0.0026 * *$

In-the-market orders

$\begin{array}{lllllllrl}\text { Morning } & 0.0065 & 0.0067 & -0.0002 & * * & 0.0056 & 0.0048 & 0.0008 & * * \\ \text { Lunch } & 0.0046 & 0.0050 & -0.0004 & * * & 0.0041 & 0.0049 & -0.0008 & * * \\ \text { Afternoon } & 0.0048 & 0.0046 & 0.0002 & * * & 0.0043 & 0.0034 & 0.0009 & * *\end{array}$

Orders at the best bid \& ask price

\begin{tabular}{|c|c|c|c|c|c|c|c|c|}
\hline Morning & 0.0028 & 0.0014 & 0.0014 & $* *$ & 0.0029 & 0.0023 & 0.0006 & $* *$ \\
\hline Lunch & 0.0010 & 0.0002 & 0.0008 & $* *$ & 0.0011 & -0.0002 & 0.0013 & $* *$ \\
\hline Afternoon & 0.0012 & -0.0005 & 0.0017 & $* *$ & 0.0014 & -0.0016 & 0.0030 & $* *$ \\
\hline \multicolumn{9}{|c|}{ Orders behind best bid \& ask price } \\
\hline Morning & -0.0001 & 0.0010 & -0.0011 & $* *$ & 0.0003 & 0.0019 & -0.0017 & $* *$ \\
\hline Lunch & -0.0008 & 0.0002 & -0.0010 & $* *$ & -0.0007 & 0.0007 & -0.0014 & $* *$ \\
\hline Afternoon & -0.0005 & 0.0000 & -0.0005 & $* *$ & -0.0007 & -0.0006 & -0.0001 & $* *$ \\
\hline
\end{tabular}


Table 5 (Cont'd) Price impact of orders

\begin{tabular}{|c|c|c|c|c|c|c|c|c|}
\hline & 5 minutes a & er order pla & ement & & 15 minute & after order & placement & \\
\hline & Insto & Retail & Ins-Retail & $t$-test & Insto & Retail & Ins-Retail & $t$-test \\
\hline Panel C: 20 & & & & & & & & \\
\hline Market ord & & & & & & & & \\
\hline Morning & 0.0073 & 0.0030 & 0.0043 & $* *$ & 0.0079 & 0.0023 & 0.0057 & $* *$ \\
\hline Lunch & 0.0050 & 0.0028 & 0.0022 & $* *$ & 0.0052 & 0.0023 & 0.0029 & $* *$ \\
\hline Afternoon & 0.0050 & 0.0025 & 0.0024 & $* *$ & 0.0053 & 0.0021 & 0.0032 & $* *$ \\
\hline In-the-mar & orders & & & & & & & \\
\hline Morning & 0.0044 & 0.0042 & 0.0002 & $* *$ & 0.0058 & 0.0028 & 0.0031 & $* *$ \\
\hline Lunch & 0.0030 & 0.0044 & -0.0015 & $* *$ & 0.0031 & 0.0029 & 0.0002 & $* *$ \\
\hline Afternoon & 0.0025 & 0.0044 & -0.0019 & $* *$ & 0.0033 & 0.0050 & -0.0017 & $* *$ \\
\hline Orders at tl & best bid \& a & price & & & & & & \\
\hline Morning & 0.0028 & 0.0024 & 0.0004 & $* *$ & 0.0040 & 0.0018 & 0.0022 & $* *$ \\
\hline Lunch & 0.0013 & 0.0007 & 0.0005 & $* *$ & 0.0016 & 0.0011 & 0.0005 & $* *$ \\
\hline Afternoon & 0.0010 & 0.0016 & -0.0006 & $* *$ & 0.0015 & 0.0010 & 0.0005 & $* *$ \\
\hline Orders beh & best bid \& & k price & & & & & & \\
\hline Morning & 0.0015 & 0.0013 & 0.0003 & $* *$ & 0.0027 & 0.0014 & 0.0013 & $* *$ \\
\hline Lunch & 0.0002 & 0.0008 & -0.0005 & $* *$ & 0.0011 & 0.0009 & 0.0002 & $* *$ \\
\hline Afternoon & 0.0001 & 0.0008 & -0.0007 & $* *$ & 0.0011 & 0.0007 & 0.0004 & $* *$ \\
\hline
\end{tabular}

This table provides changes in bid-ask midpoint 5 and 15 minutes after the submission of orders with different degree of aggressiveness during morning, lunchtime, and afternoon period, respectively, by institutional and retail traders over the three distinctive sample periods. For buy orders, the changes in midpoint price $\Delta \mathrm{mpp}=$ $\mathrm{mpp}_{t+5}-\mathrm{mppt}_{t}$; for sell orders, $\Delta \mathrm{mpp}=\mathrm{mpp}_{t+5}-\mathrm{mppt}_{t}$. Wilcoxon tests are employed to test the significance in the deference of price impact from orders placed by institutional traders and retail traders. ${ }^{* *}$ denotes statistical significance at $1 \%$. 
2003

Panel A: Price impact 5 minute after submission

Intercept

\begin{tabular}{rrr}
\multicolumn{1}{c}{ Coeff. } & \multicolumn{1}{c}{$t$-stats. } \\
\hline 0.0004 & 1.5 & \\
0.0010 & 3.0 & $* *$ \\
0.0052 & 45.8 & $* *$ \\
0.0018 & 23.7 & $* *$ \\
-0.0004 & -5.6 & $* *$
\end{tabular}

2006

\begin{tabular}{rrr}
\multicolumn{1}{c}{ Coeff. } & \multicolumn{2}{c}{$t$-stats. } \\
\hline 0.0032 & 20.1 & $* *$ \\
0.0020 & 6.1 & $* *$ \\
0.0055 & 47.9 & $* *$ \\
0.0019 & 28.8 & $* *$ \\
-0.0003 & -4.2 & $* *$
\end{tabular}

2009

\begin{tabular}{crl} 
Coeff. & \multicolumn{2}{c}{$t$-stats. } \\
\hline 0.0009 & 28.8 & $* *$ \\
0.0040 & 8.8 & $* *$ \\
0.0049 & 150.7 & $* *$ \\
0.0019 & 133.8 & $* *$ \\
0.0001 & 7.8 & $* *$
\end{tabular}

Panel B: Price impact 15 minute after submission

Intercept

Order Size

Dummy for in-the-mkt Orders

Dummy for at-the-mkt Orders

Dummy for insto traders

\begin{tabular}{lrl} 
Coeff. & \multicolumn{2}{c}{$t$-stats. } \\
\hline 0.0010 & 2.9 & $* *$ \\
0.0020 & 3.2 & $* *$ \\
0.0050 & 37.3 & $* *$ \\
0.0020 & 25.4 & $* *$ \\
-0.0004 & -4.6 & $* *$
\end{tabular}

\begin{tabular}{crc} 
Coeff. & \multicolumn{2}{c}{$t$-stats. } \\
\hline 0.0030 & 15.5 & $* *$ \\
0.0010 & 5.7 & $* *$ \\
0.0050 & 34.7 & $* *$ \\
0.0020 & 22.4 & $* *$ \\
0.0002 & -2.7 & $* *$
\end{tabular}

\begin{tabular}{crr} 
Coeff. & \multicolumn{2}{c}{$t$-stats. } \\
\hline 0.0010 & 14.9 & $* *$ \\
0.0040 & 6.6 & $* *$ \\
0.0040 & 84.0 & $* *$ \\
0.0020 & 89.6 & $* *$ \\
0.0007 & 28.7 & $* *$
\end{tabular}

This table presents the regression results for robustness test of different performance of institutional and individual orders. The dependent variable is the change in midpoint price (MPP) five (or 15) minutes after the order placement. For buy orders, $\triangle M P P=M P P_{t+5}-M P P_{t}$; for sell orders, $\triangle M P P=M P P_{t}-M P P_{t+5}$. The performance of institutional traders is measured by the coefficient of the dummy indicating orders placed by institutional traders. This regression controls for order size, order aggressiveness and stock selection by institutional and individual traders by having a dummy variable for each of the 50 stocks (results are not given above for space saving purpose). 

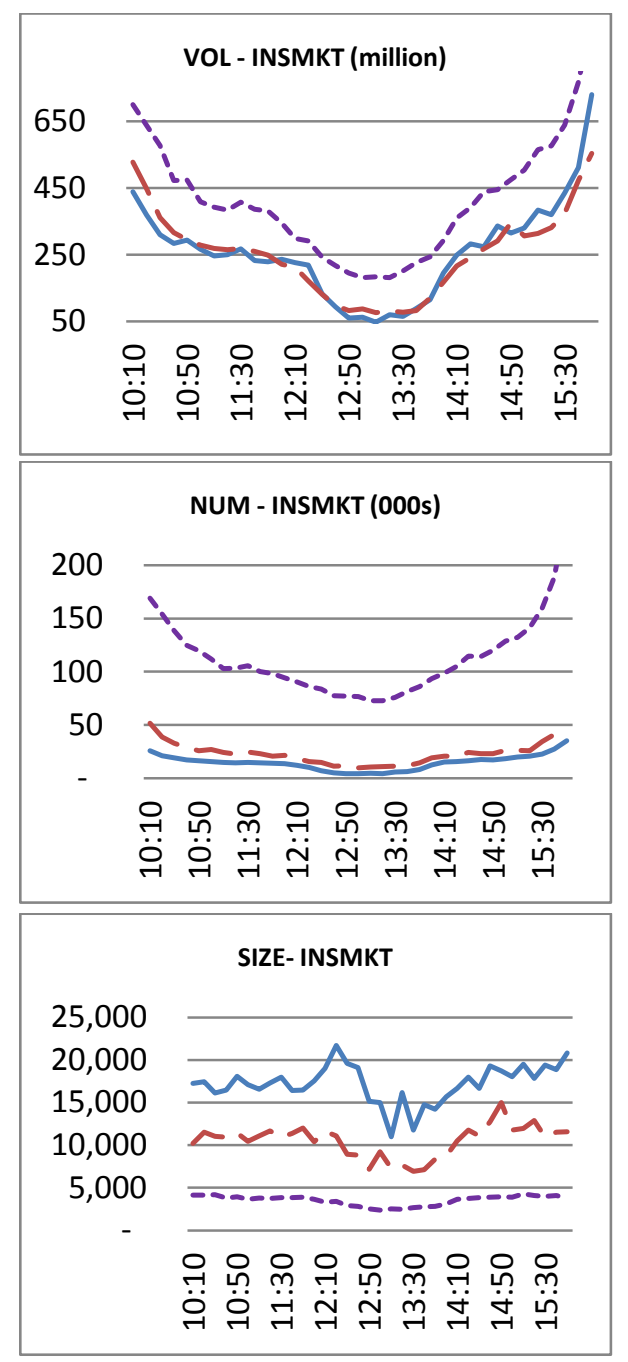
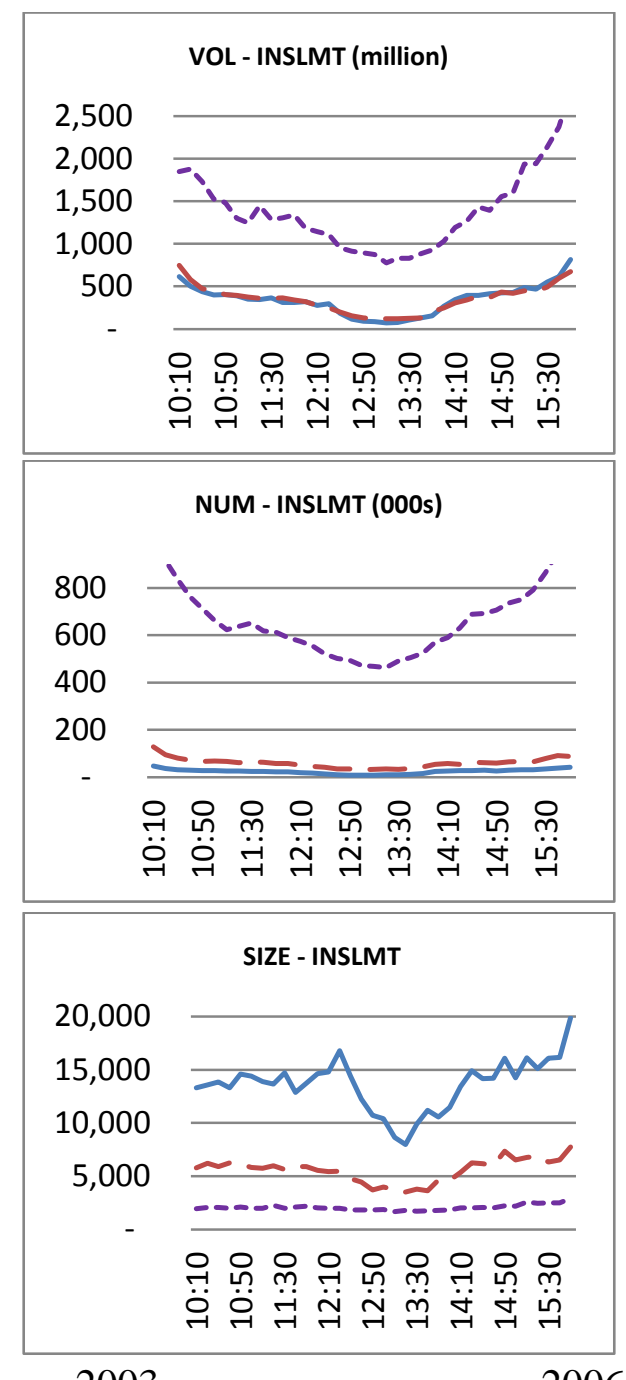
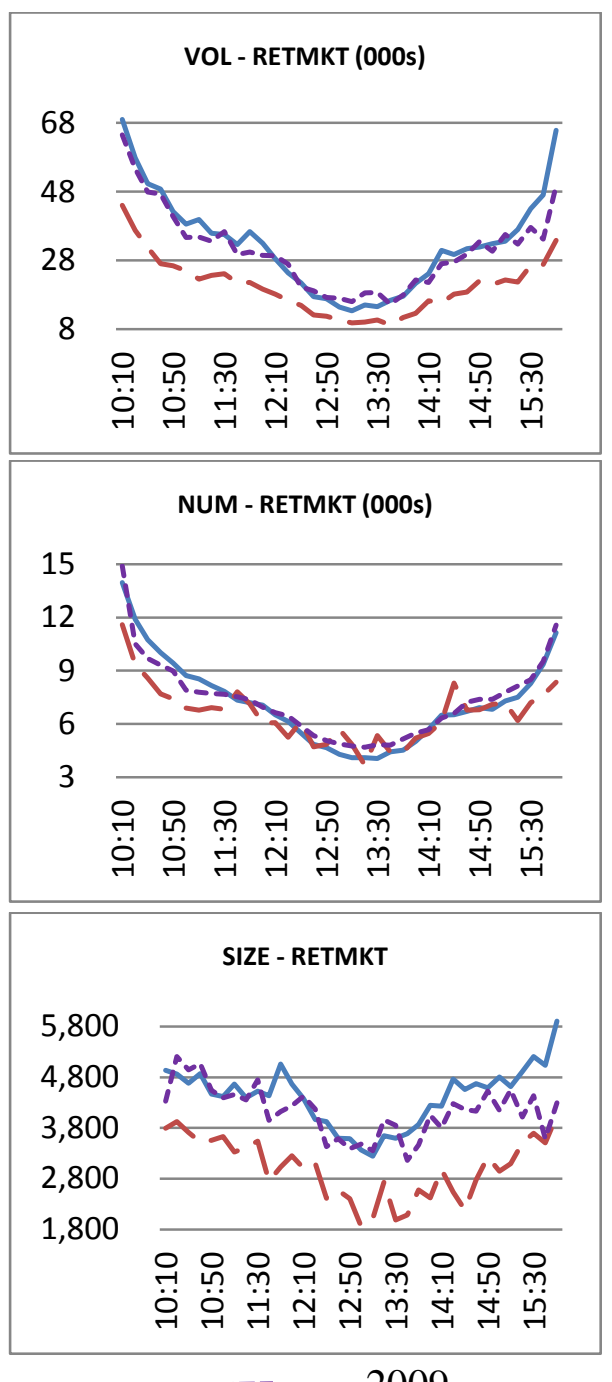
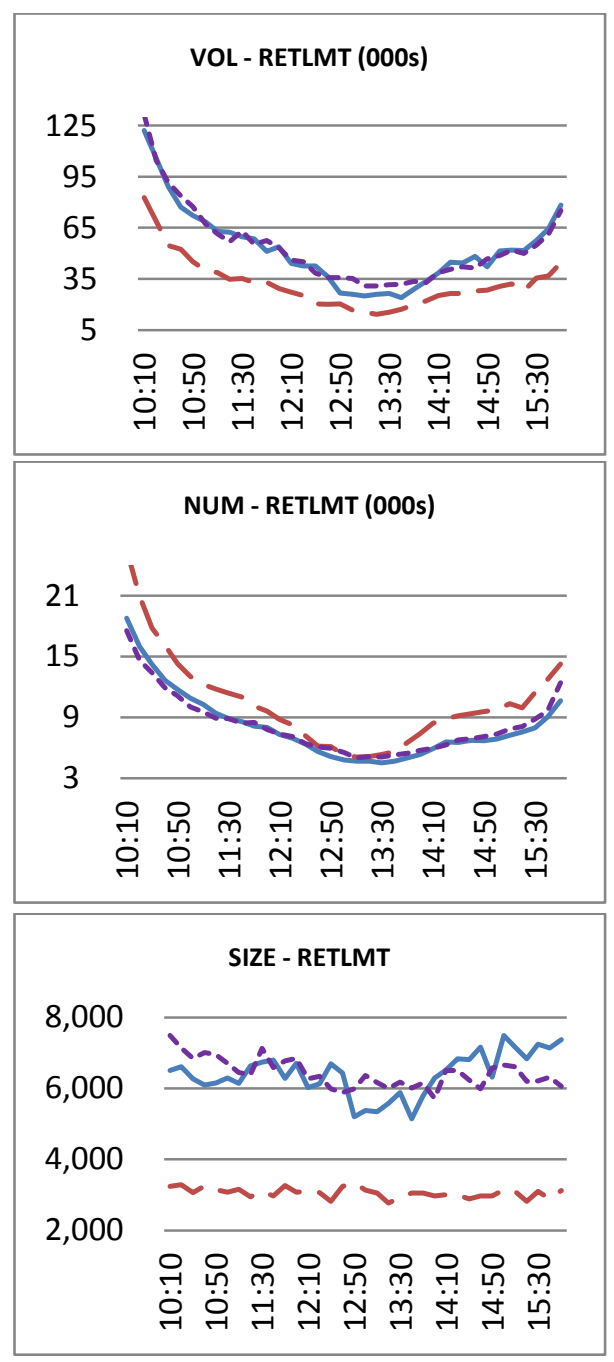

Figure 1 Order submission by institutional and retail traders

The figures depict institutional and retail traders' order submission pattern in three measures, total submitted volume in shares (VOL), the number of orders (NUM), and the average order sizes (SIZE) for limit and market orders placed over a trading day for all stocks in the S\&P/ASX 50 Index on the ASX from three samples: Jan 2 to Jun 30 2003, Jan 2 to Jun 302006 and Jan 2 to June 302009. 